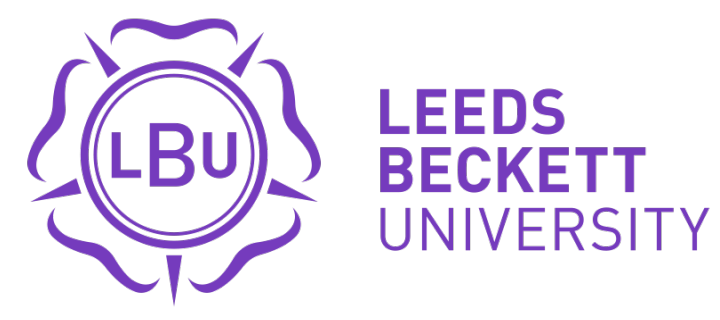

Citation:

Boos, $\mathrm{C}$ and Bakker-Dyos, $\mathrm{J}$ and Watchorn, $\mathrm{J}$ and Woods, DR and O'Hara, $\mathrm{J}$ and Macconnachie, $L$ and Mellor, A (2016) A comparison of two methods of heart rate variability assessment at high altitude. Clinical physiology and functional imaging, 37. pp. 582-587. ISSN 1475-0961 DOI: https://doi.org/10.1111/cpf.12334

Link to Leeds Beckett Repository record:

https://eprints.leedsbeckett.ac.uk/id/eprint/2234/

Document Version:

Article (Accepted Version)

(C) 2016 Crown Copyright. Clinical Physiology and Functional Imaging (C) 2016 Scandinavian Society of Clinical Physiology and Nuclear Medicine

This article is published with the permission of the Controller of HMSO and the Queen's Printer for Scotland.

The aim of the Leeds Beckett Repository is to provide open access to our research, as required by funder policies and permitted by publishers and copyright law.

The Leeds Beckett repository holds a wide range of publications, each of which has been checked for copyright and the relevant embargo period has been applied by the Research Services team.

We operate on a standard take-down policy. If you are the author or publisher of an output and you would like it removed from the repository, please contact us and we will investigate on a case-by-case basis.

Each thesis in the repository has been cleared where necessary by the author for third party copyright. If you would like a thesis to be removed from the repository or believe there is an issue with copyright, please contact us on openaccess@leedsbeckett.ac.uk and we will investigate on a case-by-case basis. 


\section{A Comparison of two methods of heart rate variability assessment at high altitude}

Running title: heart rate variability at high altitude

Christopher John Boos ${ }^{1,2}$, Josh Bakker-Dyos ${ }^{3}$, Jim Watchorn ${ }^{3}$, David Richard Woods $^{3,4,5,6}$ John Paul O’Hara ${ }^{4}$, Lee Macconnachie ${ }^{1}$ and Adrian Mellor ${ }^{3,4,7}$

${ }^{1}$ Department of Cardiology, Poole Hospital NHS Foundation trust, Poole, UK

${ }^{2}$ Dept of Postgraduate Medical Education, Bournemouth University, UK

${ }^{3}$ Defence Medical Services, Lichfield, UK

${ }^{4}$ Research Institute, for Sport, Physical Activity and Leisure, Leeds Beckett University, Leeds, UK

${ }^{5}$ Northumbria and Newcastle NHS Trusts, Wansbeck General and Royal Victoria Infirmary, Newcastle, UK

${ }^{6}$ University of Newcastle, Newcastle upon Tyne, UK

${ }^{7}$ James Cook University Hospital, Middlesborough, TS4 3BW, UK

Word count 2632

Key words heart rate variability, high altitude, ithlete, CheckMyHeart

Corresponding author: Dr Christopher J Boos, Department of Cardiology, Poole Hospital NHS Foundation Trust, Longfleet Rd. Poole, Dorset, BH15 2JB

Tel 0120244 2572; fax 01202442754 email: christopherboos @ hotmail.com 


\begin{abstract}
Heart rate variability (HRV) is a useful index of autonomic function and has been linked to the development of high altitude (HA) related illness. However, its assessment at HA has been undermined by the relative expense and limited portability of traditional HRV devices which have mandated at least a five minute heart rate recording. In this study the portable ithlete ${ }^{\mathrm{TM}} \mathrm{HRV}$ system, which uses a 55 second recording, was compared with a reference method of HRV which utilises a five minute electrocardiograph recording (CheckMyHeart $\left.{ }^{\mathrm{TM}}\right)$. The root mean squares of successive R-R intervals (RMSSD) for each device was converted to a validated HRV score (lnRMSSDx20) for comparison. Twelve healthy volunteers were assessed for HRV using the two devices across seven time points at HA over 10 days. There was no significant change in the HRV values with either the ithlete $(\mathrm{P}=0.3)$ or the CheckMyHeart $^{\mathrm{TM}}(\mathrm{p}=0.19)$ device over the seven altitudes. There was also a strong overall correlation between the ithlete ${ }^{\mathrm{TM}}$ and CheckMyHeart ${ }^{\mathrm{TM}}$ device $(\mathrm{r}=0.86 ; 95 \%$ confidence interval: 0.79 to 0.91 ). The HRV was consistently, though nonsignificantly higher with ithlete ${ }^{\mathrm{TM}}$ than with the CheckMyHeart ${ }^{\mathrm{TM}}$ device (mean difference [bias] $1.81 ; 95 \% \mathrm{CI}-12.3$ to 8.5$)$. In summary the ithlete ${ }^{\mathrm{TM}}$ and CheckMyHeart ${ }^{\mathrm{TM}}$ system provide relatively similar results with good overall agreement at $\mathrm{HA}$.
\end{abstract}




\section{Introduction}

The autonomic nervous system (ANS) plays a pivotal role in the regulation of a number of physiological processes. ANS control of the heart via both sympathetic and parasympathetic ANS innervation leads to continuous beat to beat deviations in heart rate and RR intervals which can be quantified as changes in heart rate variability (HRV) (Weimer, 2010). Hence, quantification of HRV is an important method of assessing ANS function in vivo. It has been shown that a number of factors such as inter-current illness, cardiovascular disease, physical overtraining and even mental stress can lead to increased cardiac sympathetic activation and a reduction in HRV (Lahiri et al., 2008; Kiviniemi AM et al., 2014; Sassi et al., 2015). This has led to a number of useful clinical applications in the field of sport and exercise medicine such as the assessment of physical fitness and overtraining as well as competitive readiness (Da Silva et al., 2015; Routledge et al., 2010; D'Ascenzi F et al., 2014; Kiviniemi AM et a.,1 2014).

Traditional methods of HRV have required expensive and specialised equipment and processing software with the need to record the cardiac activity for at least five minutes (Task Force 1996). There have been significant recent technological advances with increasing miniaturization of available HRV devices that provide full disclosure single channel ECG recordings with internal software to provide accurate assessment of HRV. Whilst considerably more affordable than traditional methods these devices are still relatively expensive, require the purchase of disposable ECG electrodes and may not be practical for everyday use. There has been a significant expansion in non-invasive HRV devices which utilise either finger sensors or chest straps which can wirelessly link to portable devices and mobile phones for data 
analysis. They provide a portable, cheap and more practical method of assessing HRV. One of the key HRV parameters which is well suited to these ultra-portable HRV devices is the root mean square of successive R-R intervals (RMSSD). The RMSSD is a reliable time domain measure of vagally mediated cardiac control and parasympathetic activity (Task Force 2006). It has the advantage over several other HRV outputs in that it can be reliably assessed with ultrashort recordings, (over less $\leq 1$ minute), improving its applicability and use compliance in athletes and others (Nussinovitch U et al., 2011; Nakamura et al., 2015; Esco and Flatt 2014; Flatt and Esco 2015). Moreover, the RMSSD appears to be less prone to the influence of respiration than many other HRV parameters and has been shown to be a robust marker of physical and mental stress (Grieco C et al., 2014; Saboul et al., 2013). The ithelte $^{\mathrm{TM}}$ (HRV Fit Ltd, Southampton, UK) device is one of best known ultra-portable HRV devices which utilises a 55 second recording to provide a RMSSD derived HRV score. It has been shown to have excellent agreement (correlation coefficient of 0.99) with that obtained from a standard five minute electrocardiographic recording (Flatt and Esco 2013).

Another area where HRV has been of increasing relevance has been in the field of high altitude (HA) medicine. There is increasing evidence to suggest that HA exposure leads to altered ANS activity and changes in HRV which may be linked to the development of acute mountain sickness (AMS) (Sevre et al., 2001; Huang et al., 2010; Karinen et al., 2012). The simplicity of the ithlete ${ }^{\mathrm{TM}}$ would circumvent many of the challenges faced by studying HRV at HA; however it has never been formally validated in this environment. In this study we sought to assess the ithlete ${ }^{\mathrm{TM}} \mathrm{HRV}$ 
smart phone application in comparison with a reference electrocardiographic HRV device at HA.

\section{Materials and Methods}

\subsection{Subjects}

This was a prospective observational study of 12 healthy British military servicemen and women on expedition to the Dhaulagiri region of the Himalayas in Nepal. All Subjects were studied on arrival at Kathmandu (1400m, day 0), at 1045m (day 2), 1600m (day 3), 2050m (day 5), 2500m (day 6), 3100m (day 7) and 3600m (day 9). The study was approved by the Ministry of Defence Research and Medical Ethics. All participants underwent written informed consent. Resting recordings of oxygen saturations (SpO2) were performed using a Nellcor N-20P pulse oximeter (Nellcor Puritan Bennett, Coventry, UK). Baseline heart rate and blood pressure were measured using an automated blood pressure cuff with the subject sat upright and rested for >10 minutes (M6 Omron Healthcare, Milton Keynes, UK). Symptoms of acute mountain sickness were assessed using the Lake Louise Scoring system. The LLS scores allocates a score of 0-3 (symptom not present to severe) for symptoms of AMS (headache, gastrointestinal symptoms, fatigue/weakness, dizzy/lightheadedness, difficulty sleeping). A total score of $>3$ in the presence of a headache is consistent with AMS.

\subsection{Assessment of Heart Rate Variability}

Participants were all studied at approximately 0700 in the morning post micturition but prior to breakfast or caffeine. All subjects were seated, wearing warm clothing in 
a tent for at least 5 minutes before the HRV recordings were obtained (Flatt et al 2013). HRV variability was obtained using the ithlete ${ }^{\mathrm{TM}}$ (HRV Fit Ltd. Southampton, UK) and CheckMyHeart ${ }^{\mathrm{TM}}(\mathrm{CMH}$, Daily Care Biomedical, Taiwan) devices.

For the ithlete ${ }^{\mathrm{TM}}$ each subject wore an elasticated chest strap heart rate monitor (Cardiosport Bluetooth) that was fastened securely around the upper thorax at the level of the xiphoid process. All ithlete ${ }^{\mathrm{TM}} \mathrm{HRV}$ data was collected with the ithlete ${ }^{\mathrm{TM}}$ ECG receiver and ithlete ${ }^{\mathrm{TM}}$ application on the subjects apple smart phone as previously described (Flatt and Esco 2013). Two 55 second recordings were obtained with the ithlete during the first and last minute of a five minute HRV recording obtained by a CheckMyHeart ${ }^{\mathrm{TM}}$ device. During these ithlete ${ }^{\mathrm{TM}}$ recordings breathing prompts were followed and the average of the two ithlete ${ }^{\mathrm{TM}}$ readings were used. This prompt uses an animation to guide a control the overall breathing rate as well as the inspiratory and expiratory phases. The CheckMyHeart ${ }^{\mathrm{TM}} \mathrm{HRV}$ device is a validated battery powered portable HRV machine that utilises two skin ECG electrodes which were placed at the right sternal edge and over the apex beat to acquire a continuous five minute ECG recording for HRV as previously described (Wen et al 2007). All stored recordings were later exported via USB hook up for full data analysis.

The ithlete ${ }^{\mathrm{TM}}$ modifies the acquired RMSSD by taking the natural log transformation and multiplying by twenty $(\operatorname{lnRMSSD} \times 20)$ to provide a more interpretable figure for the user on a $\sim 100$ point scale (Wegerif, 2009). Hence this was also undertaken on the RMSSD data obtained from the CheckMyHeart ${ }^{\mathrm{TM}}$ device to compare with the ithlete $^{\mathrm{TM}}$ as previously described (Flatt et al 2013). 


\subsection{Statistical Analysis}

Data were analysed using GraphPad InStat version 3.05 and with all graphical figures presented using GraphPad Prism version 4.00 for Windows (GraphPad Software, San Diego, CA, USA; www.graphpad.com). The Kolmogorov-Smirnov test was undertaken to assess normality of all continuous data. The results were presented as mean \pm standard deviation (SD). As the HRV data for both ithlete ${ }^{\mathrm{TM}}$ and CheckMyHeart $^{\mathrm{TM}}$ were normally distributed paired comparisons of HRV measures were performed with a paired $\mathrm{T}$ test and correlations were quantified using the Pearson correlation coefficient $\pm 95 \%$ confidence interval $(\mathrm{CI})$. Time dependent changes of continuous data within each group were assessed using repeated measures ANOVA and Tukey post-hoc test and the Friedman Test with the Dunn post-test for parametric and non-parametric data respectively. Comparison of HRV scores with increasing LLS Scores were assessed using the Kruskal-Wallis (nonparametric ANOVA) Test. Agreement in the paired sampling of the ithlete ${ }^{\mathrm{TM}}$ at the end of the first and fifth minute were assessed using the coefficient of variation and Pearson Correlation coefficient. Agreements in HRV measurement between ithlete ${ }^{\mathrm{TM}}$ and CheckMyHeart ${ }^{\mathrm{TM}}$ were assessed using Bland-Altman plots (Bland and Altman., 1986) in which the difference between the two values were compared with the average values from the comparative two readings. The bias was defined as the mean $\pm \mathrm{SD}$ of the difference between the readings. Reasonable agreement was defined as $<5 \%$ of readings being within $1.96 \mathrm{SD}(95 \% \mathrm{CI})$ from the mean. A p value of $<0.05$ was considered significant for all comparisons.

\section{Results}


The study group consisted of 12 volunteers with an average age of $26.0 \pm 2.3$ (range 23-32) years (9 men and 3 women). Their body weight was $71.60 \pm 6.8 \mathrm{~kg}$ with a height of $172.8 \pm 5.6 \mathrm{~cm}$ and body mass index of $24.0 \pm 1.6 \mathrm{~kg} / \mathrm{m}^{2}$. There were no smokers in the study group and no subjects took any regular medications other than the oral contraceptive pill. There was no significant change in the LLS scores with increasing HA ( $\mathrm{p}=0.16)$ and no cases of acute mountain sickness, although increasing altitude did lead to a significant fall in oxygen saturations $(97.9 \pm 0.7 \%$ at baseline vs $92.9 \pm 1.2 \%$ at $3600 \mathrm{~m})$ and heart rate $(62.3 \pm 9.4$ at baseline vs $74.8 \pm 12.3 /$ minute at $3600 \mathrm{~m}$ ) (table 1). There were only two subjects with a LLS score of 3 and no LLS scores $>3$. There was no change in the HRV score with increasing LLS (figure 1; $\mathrm{p}=0.52)$

There was no significant change in the RMSSD-derived HRV values across all the seven altitudes with either the ithlete ${ }^{\mathrm{TM}}(\mathrm{P}=0.3)$ or the CheckMyHeart ${ }^{\mathrm{TM}}$ Device $(\mathrm{p}=0.19)$ (figure 2). Further, there were no significant differences in RMSSD-derived HRV between the ithelte ${ }^{\text {TMTM }}$ and CheckMyHeart ${ }^{\text {TM }}$ Device at any of the seven altitudes $(\mathrm{p}=0.47)$.

There was a significant correlation between the first and second readings of the Ithlete $^{\mathrm{TM}}$ taken at the end of one and five minutes $(\mathrm{r}=0.89 ; 0.82-0.93$; coefficient of variation 5.5\%). The first $(r=0.80 ; 0.70-0.87: \mathrm{p}<0.0001)$ and second $(\mathrm{r}=0.8395 \%$ confidence interval: $0.74-0.89$ ) ithlete ${ }^{\mathrm{TM}} \mathrm{HRV}$ readings both strongly correlated with the five minute acquired CheckMyHeart ${ }^{\mathrm{TM}}$ HRV scores. However, the strongest correlation between the ithlete ${ }^{\mathrm{TM}}$ with the CheckMyHeart ${ }^{\mathrm{TM}}$ was obtained when the average of the two ithlete ${ }^{\mathrm{TM}}$ readings were used ( $\mathrm{r}=0.86 ; 0.79$ to 0.91 ) (figure 3 ). 
On Bland-Altman comparisons of the two methods of HRV assessment the values for RMSSD derived HRV were consistently but non-significantly higher with averaged ithlete $^{\mathrm{TM}}$ than with the CheckMyHeart ${ }^{\mathrm{TM}}$ device (mean difference [bias] 1.81; 95\% limit of agreement -12.3 to 8.5 ) (figure 4).

\section{Discussion and Conclusions}

To the authors knowledge this is the first study to evaluate HRV at HA using two differing methods of HRV assessment. In this study the ithlete ${ }^{\mathrm{TM}}$ smart phone HRV application using a chest-borne heart rate sensor was compared with that of the CheckMyHeart ${ }^{\mathrm{TM}}$ electrocardiograph derived system over 55 second and five minute recordings respectively. The overall agreement between methods was reasonably good across the differing altitudes. HRV readings were consistently, though nonsignificantly higher with the ithlete ${ }^{\mathrm{TM}}$ than with the CheckMyHeart ${ }^{\mathrm{TM}}$ System.

The rational for this study was clear. HRV has evolved as an increasingly useful tool to assess physical and mental fitness (da Silva et al., 2015). However, traditional HRV assessments require at least five minutes of data recording, are more expensive and provide a plethora of highly complex time and frequency domain derived data

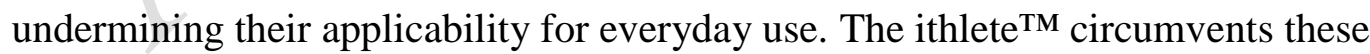
issues by providing an easy to understand intuitive RMSSD derived HRV reading obtained over 55 seconds which can be recorded to a mobile phone or portable tablet (Flatt and Esco., 2013). In the only previous comparative study to compare the ithlete $^{\mathrm{TM}}$ to a reference HRV device a near perfect correlation between the ithlete ${ }^{\mathrm{TM}}$ and a five minute electrocardiography HRV device was observed in 25 healthy 
subjects at sea level $(r=0.99, \mathrm{p}<0.001)$ (Flatt and Esco 2013). On Bland Altman analysis the level of agreement was -2.57 to 2.63 above the constant bias (constant error) of -0.03 . This is clearly much higher level of agreement than that obtained in our study. However, we believe this difference relates to the environmental and methodological differences between the two studies. The previous ithlete ${ }^{\mathrm{TM}}$ validation study was performed in a temperature controlled laboratory at sea level. Conversely, our study was performed across several different time points and altitudes under very remote and challenging field conditions at HA. Secondly, the breathing prompts were only followed during the ithlete ${ }^{\mathrm{TM}}$ recordings within the five minute CheckMyHeart ${ }^{\mathrm{TM}}$ recording and not during the entire five minutes. This was because the CheckMyHeart ${ }^{\mathrm{TM}}$ device does not provide breathing prompts which were only available during the ithlete ${ }^{\mathrm{TM}}$ recording. This could explain the consistent, but marginally higher, HRV values for the ithlete ${ }^{\mathrm{TM}}$. Whilst we could have maintained the breathing prompts for the non-ithlete ${ }^{\mathrm{TM}}$ recording periods we were eager to assess the comparative differences in the two devices under their directed use. The subjects were instructed to undertake slow relaxed breathing during the non-ithlete ${ }^{\mathrm{TM}}$ CheckMyHeart ${ }^{\mathrm{TM}}$ recording periods.

In this study we aimed to assess the utility and validity of a more simplified measure of HRV at HA as there has been accumulating data to suggest that hypoxia and HA lead to a reduction in HRV with a reduction in parasympathetic activity and a relative increase in sympathetic activity (Chen et al., 2008; Botek et al., 2015). In these previous studies the ascents were far more dramatic and rapid than in our current study which more closely reflects a real life HA trek. For example, in a previous study of 27 volunteers Chen et al noted significant changes in several time and 
frequency domain measures of HRV but their ascent was from 555 to $3180 \mathrm{~m}$ in a cable car in $<3$ hours (Chen et al., 2008). And in another study Botek et al noted significant changes in HRV following abrupt exposure to normobaric hypoxia $(\mathrm{FiO} 2=9.6 \%)$ which is a degree of hypoxia akin to that of $>4000 \mathrm{~m}$ (Botek et al.; 2015). There is some data to suggest that changes in HRV may be linked or even predictive of AMS though this still remains controversial (Lanfranchi et al., 2005; Chen et al., 2008; Koehle et al., 2010; Willie et al., 2012; Song et al., 2013; Karinen et al., 2012). This has important clinical implications as travel to HA has significantly increased in the last 10 years and AMS affects $\geq 35 \%$ of persons traveling to altitudes 23000m (Croughs et al., 2014). Previous studies assessing HRV and its links to HA have been partly undermined by the relatively small sample size. Hence, the ability to utilise more portable HRV devices such as the ithlete ${ }^{\mathrm{TM}}$ or the CheckMyheart ${ }^{\mathrm{TM}}$ device may have competitive value over several other HRV platforms. Given the sensitivity of the RMSSD to changes in parasympathetic activity and its recognised alterations at HA this created another persuasive reason to further explore the validity of the ithlete ${ }^{\mathrm{TM}}$ at HA. RMSSD is just one of the many time domain measures of HRV (eg SDNN, SDANN, pNN50). However, all of these measurements of shortterm variation estimate high frequency variations in heart rate and have been shown to be highly correlated (Task Force., 1996).

This study has several limitations that need to be acknowledged. The sample size of this study was small however as the subjects were studied at seven different altitudes this significantly increased the data which is larger than the vast majority of HA HRV studies to date. The altitude achieved was moderate (with no reported cases of AMS) and hence the results cannot necessarily apply to much higher altitudes though the 
consistency of the data and good agreement across all seven altitudes is encouraging. Despite it obvious portability and simplicity, the ithlete ${ }^{\mathrm{TM}}$ only records one parameter of HRV. Whereas the CheckMyHeart ${ }^{\mathrm{TM}}$ and other electrocardiograph HRV devices which use five minute recordings are able to provide detailed frequency domain and power spectral analysis allowing a more in depth assessment of changes in autonomic tone and sympatho/vagal balance.

In conclusion the ithlete ${ }^{\mathrm{TM}} \mathrm{HRV}$ system is a ultraportable HRV assessment system utilising a 55 second recording that has shown a good correlation with a reference method of HRV using a five minute recording from a surface ECG. It has potential clinical applicability for the study of HRV at HA and comparative data from larger studies would be helpful.

\section{Acknowledgements}

The authors would like to thank the Surgeon General and the Defence Medical Services for the support and for the subjects who undertook what was a very challenging clinical study to perform.

\section{Conflict of Interest}

All authors have read and approved the manuscript and that there is no conflict of interest to declare. 


\section{References}

1. Weimer LH Autonomic testing: common techniques and clinical applications. Neurologist (2010); 16:215-22.

2. Lahiri MK, Kannankeril PJ, Goldberger JJ.Assessment of autonomic function in cardiovascular disease: physiological basis and prognostic implications. J Am Coll Cardiol (2008); 51:1725-33.

3. Kiviniemi AM, Tulppo MP, Hautala AJ, Vanninen E, Uusitalo AL.Altered relationship between $\mathrm{R}-\mathrm{R}$ interval and $\mathrm{R}-\mathrm{R}$ interval variability in endurance athletes with overtraining syndrome. Scand J Med Sci Sports (2014); 24:e77.

4. Sassi R, Cerutti S, Lombardi F, Malik M, Huikuri HV, Peng CK, Schmidt G, Yamamoto Y; Document Reviewers:, Gorenek B, Lip GY, Grassi G, Kudaiberdieva G, Fisher JP, Zabel M, Macfadyen R. Advances in heart rate variability signal analysis: joint position statement by the e-Cardiology ESC Working Group and the European Heart Rhythm Association co-endorsed by the Asia Pacific Heart Rhythm Society. Europace (2015); Jul 14. pii: euv015. [Epub ahead of print].

5. da Silva VP, de Oliveira NA, Silveira H, Mello RG, Deslandes AC Heart rate variability indexes as a marker of chronic adaptation in athletes: a systematic review. Ann Noninvasive Electrocardiol (2015); 20:108-18.

6. Routledge $\mathrm{FS}^{1}$, Campbell TS, McFetridge-Durdle JA, Bacon SL.Improvements in heart rate variability with exercise therapy. Can J Cardiol (2010); 26:303-12.

7. D'Ascenzi $\mathrm{F}^{1}$, Alvino F, Natali BM, Cameli M, Palmitesta P, Boschetti G, Bonifazi M, Mondillo S. Precompetitive assessment of heart rate variability in elite female athletes during play offs. Clin Physiol Funct Imaging (2014); 34:230-6. 
8. Heart rate variability: standards of measurement, physiological interpretation and clinical use. Task Force of the European Society of Cardiology and the North American Society of Pacing and Electrophysiology. Circulation (1996); 93:1043-65.

9. Esco MR, Flatt AA. Ultra-Short-Term Heart Rate Variability Indexes at Rest and Post-Exercise in Athletes: Evaluating the Agreement with Accepted Recommendations. Journal of Sports Science and Medicine (2014); 13:535 541.

10. Flatt AA, Esco MR. Heart rate variability stabilization in athletes: towards more convenient data acquisition. Clin Physiol Funct Imaging (2015) Mar 9. doi: 10.1111/cpf.12233. [Epub ahead of print].

11. Nussinovitch U, Elishkevitz KP, Katz K, Nussinovitch M, Segev S, Volovitz B, Nussinovitch N. Reliability of Ultra-Short ECG Indices for Heart Rate Variability. Ann Noninvasive Electrocardiol (2011); 16:117-22.

12. Nakamura FY, Flatt AA, Pereira LA, Ramirez-Campillo R, Loturco I ${ }^{3}$, Esco $\mathrm{MR}^{2}$.Ultra-Short-Term Heart Rate Variability is Sensitive to Training Effects in Team Sports Players. J Sports Sci Med (2015); 14:602-5.

13. Grieco $\mathrm{CR}^{1}$, Colberg SR, Somma CT, Thompson AG, Vinik AI.Acute effect of breathing exercises on heart rate variability in type 2 diabetes: a pilot study. $\mathbf{J}$ Altern Complement Med (2014); 20:642-8.

14. Saboul D, Pialoux V, Hautier C.The impact of breathing on HRV measurements: implications for the longitudinal follow-up of athletes. Eur $\mathbf{J}$ Sport Sci (2013); 13:534-42. 
15. Flatt AA, Esco MR. Validity of the ithlete ${ }^{\mathrm{TM}}$ Smart Phone Application for Determining Ultra-Short-Term Heart Rate Variability. J Hum Kinet (2013); 39:85-92.

16. Karinen HM, Uusitalo A, Vähä-Ypyä H, Kähönen M, Peltonen JE, Stein PK, Viik J, Tikkanen HO.Heart rate variability changes at $2400 \mathrm{~m}$ altitude predicts acute mountain sickness on further ascent at 3000-4300 m altitudes. Front Physiol (2012); 3:336.

17. Huang HH, Tseng CY, Fan JS, Yen DH, Kao WF, Chang SC, Kuo TB, Huang $\mathrm{CI}$, Lee $\mathrm{CH}$. Alternations of heart rate variability at lower altitude in the predication of trekkers with acute mountain sickness at high altitude. Clin J Sport Med (2010); 20:58-63.

18. Sevre K, Bendz B, Hankø E, Nakstad AR, Hauge A, Kåsin JI, Lefrandt JD, Smit AJ, Eide I, Rostrup M. Reduced autonomic activity during stepwise exposure to high altitude. Acta Physiol Scand (2001); 173:409-17.

19. Wegerif SC. U.S. Patent Application (2009); 12/565,717.

20. Bland J, Altman D. Statistical methods for assessing agreement between two methods of clinical measurement. Lancet (1986); 1: 307-310.

21. Botek M, Krejčí J, De Smet S, Gába A, McKune AJ. Heart rate variability and arterial oxygen saturation response during extreme normobaric hypoxia. Auton Neurosci (2015); 190:40-5.

22. Song H, Ke T, Luo WJ, Chen JY.Non-high altitude methods for rapid screening of susceptibility to acute mountain sickness. BMC Public Health (2013); 13:902

23. Wille M, Mairer K, Gatterer H, Philippe M, Faulhaber M, Burtscher M. 
Changes in cardiac autonomic activity during a passive 8 hour acute exposure to $5500 \mathrm{~m}$ normobaric hypoxia are not related to the development of acute mountain sickness. Int J Sports Med (2012); 33:186-91.

24. Koehle MS, Guenette JA, Warburton DE. Oximetry, heart rate variability, and the diagnosis of mild-to-moderate acute mountain sickness. Eur J Emerg Med (2010); 17:119-22.

25. Chen YC, Lin FC, Shiao GM, Chang SC. Effect of rapid ascent to high altitude on autonomic cardiovascular modulation. Am J Med Sci (2008); 336:248-53.

26. Lanfranchi PA, Colombo R, Cremona G, Baderna P, Spagnolatti L, Mazzuero G, Wagner P, Perini L, Wagner H, Cavallaro C, Giannuzzi PAutonomic cardiovascular regulation in subjects with acute mountain sickness. Am J Physiol Heart Circ Physiol (2005); 289:H2364-72.

27. Croughs M, Van Gompel A, Rameckers S, Van den Ende J. Serious altitude illness in travelers who visited a pre-travel clinic. J Travel Med (2014); 21:4039. 
Table 1 Changes in Key physiological variables with changing altitude

\begin{tabular}{|c|c|c|c|c|c|c|c|c|}
\hline Altitude & $1400 \mathrm{~m}$ & $1100 \mathrm{~m}$ & $1600 \mathrm{~m}$ & $2000 \mathrm{~m}$ & $2500 \mathrm{~m}$ & $3110 \mathrm{~m}$ & $3600 \mathrm{~m}$ & \\
\hline Heart rate/minute & $62.3 \pm 9.4$ & $62.8 \pm 12.7$ & $64.9 \pm 14.1$ & $64.6 \pm 13.9$ & $67.6 \pm 13.1$ & $69.8 \pm 12.1$ & $74.8 \pm 12.3^{*}$ & 0.002 \\
\hline $\begin{array}{l}\text { Systolic blood } \\
\text { pressure, } \mathrm{mmHg}\end{array}$ & $131.6 \pm 13.2$ & $122.8 \pm 11.2$ & $121.8 \pm 10.8^{*}$ & $130.3 \pm 13.2$ & $128.8 \pm 13.1$ & $131.3 \pm 14.1$ & $129.1 \pm 16.0$ & 0.006 \\
\hline $\begin{array}{l}\text { Diastolic blood } \\
\text { pressure, } \mathrm{mmHg}\end{array}$ & $79.5 \pm 7.5$ & $73.9 \pm 10.8$ & $73.4 \pm 9.0$ & $78.8 \pm 9.9$ & $76.3 \pm 8.3$ & $81.2 \pm 9.0$ & $79.8 \pm 9.3$ & 0.03 \\
\hline LLS & $0.1 \pm 0.3$ & $0.6 \pm 0.9$ & $0.6 \pm 0.5$ & $0.5 \pm 0.7$ & $0.3 \pm 0.7$ & $0.9 \pm 1.0$ & $0.6 \pm 0.8$ & 0.16 \\
\hline $\mathrm{SpO} 2, \%$ & $97.9 \pm 0.7$ & $98.0 \pm 1.0$ & $96.8 \pm 1.2$ & $97.0 \pm 1.3$ & $95.4 \pm 1.2 *$ & $93.0 \pm 1.7 *$ & $92.9 \pm 1.2 *$ & $<0.001$ \\
\hline
\end{tabular}




\section{Legend for Figures}

Figure 1 Changes in the Heart Variability Score with increasing Lake Louise Scores.

Figure 2 Paired changes in heart Rate Variability for the ithlete ${ }^{\mathrm{TM}}$ versus

CheckMyHeart ${ }^{\mathrm{TM}}$ at high altitude

Figure 3 Correlation between ithlete ${ }^{\mathrm{TM}}$ and CheckMyHeart ${ }^{\mathrm{TM}}$ Heart Variability Score at high altitude

Figure 4 Bland-Altman plots comparing ithlete ${ }^{\mathrm{TM}}$ and CheckMyHeart ${ }^{\mathrm{TM}}$ Heart Variability Scores at high altitude. The mean bias and the $95 \%$ confidence interval of the bias (2 standard deviations) are shown. 


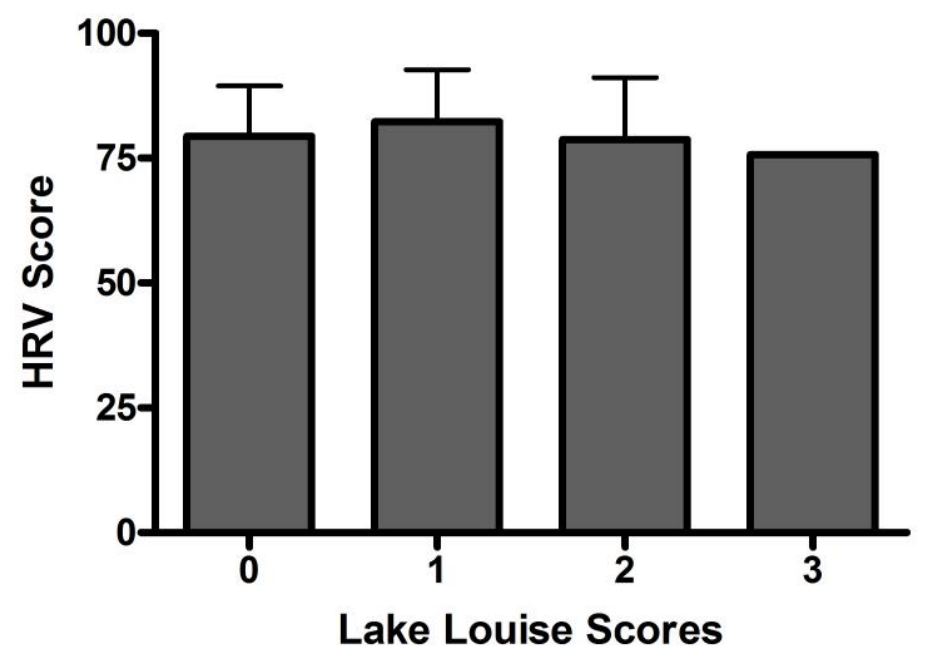

Figure 1 Changes in the Heart Variability Score with increasing Lake Louise Scores.

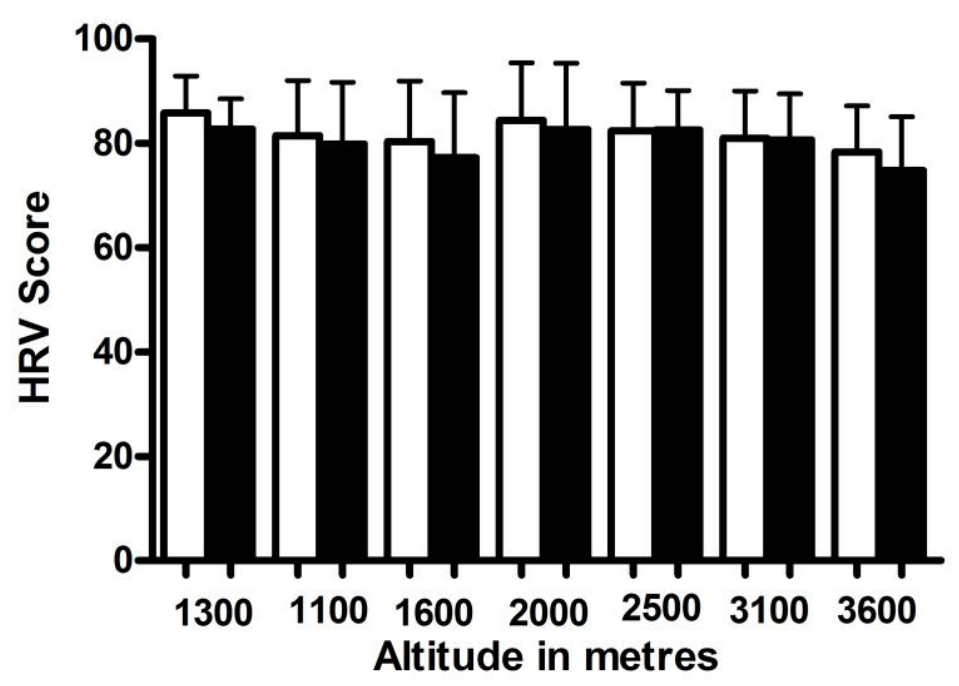

Figure 2 Paired changes in heart Rate Variability for the ithlete ${ }^{\mathrm{TM}}$ versus

CheckMyHeart ${ }^{\mathrm{TM}}$ at high altitude 


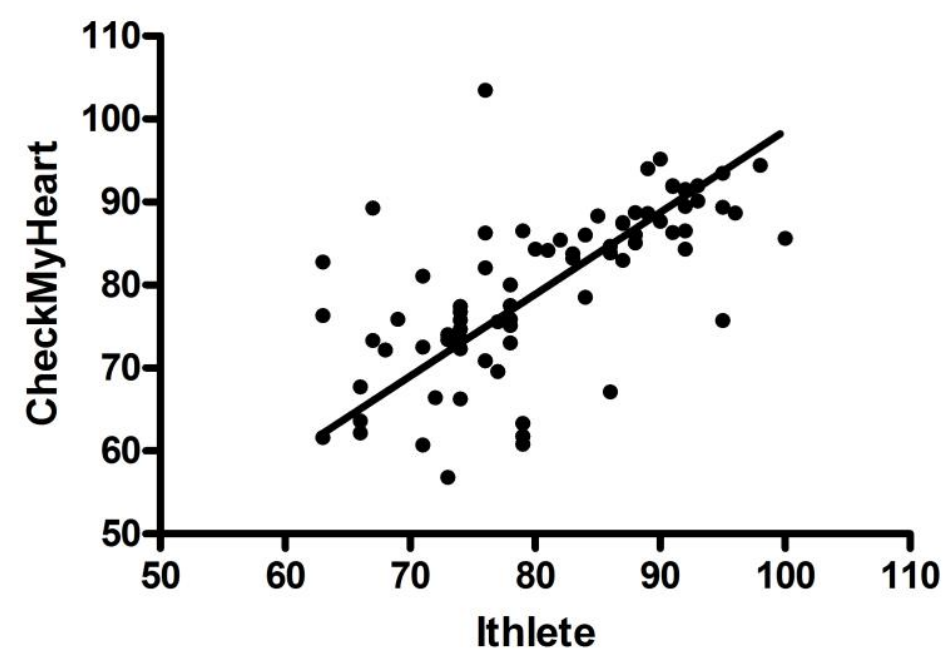

Figure 3 Correlation between ithlete ${ }^{\mathrm{TM}}$ and CheckMyHeart ${ }^{\mathrm{TM}}$ Heart Variability Score at high altitude

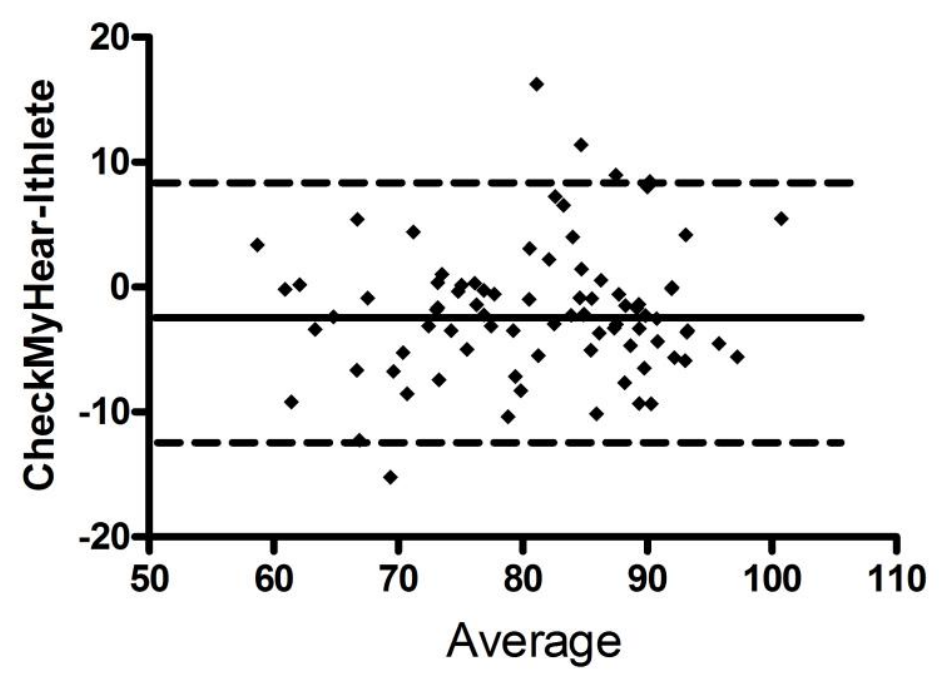

Figure 4 Bland-Altman plots comparing ithlete ${ }^{\mathrm{TM}}$ and CheckMyHeart ${ }^{\mathrm{TM}}$ Heart Variability Scores at high altitude. The mean bias and the $95 \%$ confidence interval of the bias (2 standard deviations) are shown. 